2. Locher $C$, Batumona $B$, Afchain $P$ et al. (2018) Digestive and Liver Disease 50, 15-19.

3. Pan S.Y. and Morrison H. (2011). Epidemiology of cancer of the small intestine. World J Gastrointest Oncol 3(3), 33-42.

4. Cardoso $H_{.}$, Rodrigues JT, Marques $M$, et al (2015). Malignant Small Bowel Tumors: Diagnosis, Management and Prognosis. Tumores Malignos do Intestino Delgado: Diagnóstico, Tratamento e Prognóstico. Ordem dos Médicos, Acta Med Port 28(4), 448-456.

5. Nguyê̂n Văn Giao (2010). Nghiên cứu đặc điểm lâm sà̀ng, cận lâm sàng và đánh giá kết quả điều trị phẩu thuật ung thư ruột non, Luận văn Bác sỹ chuyên khoa cấp II Ngoại tiêu hóa, Trường Đại hoc Y Hà Nôi.

6. Vằn Tân, Trân Vĩnh Hưng và Dương Thanh Hải (2016). U ruột non: đăc điểm, phấu thuật và kết quả tại Bệnh viện Bình Dân. Tạp chí Y học Tp HCM, 20(立), 34-37

7. Dai B, Ginstizzi AG and Demazine NS (1991). Les tumeurs malignes de l'intestin grêle: à propos de 55 cas. Lyon chir, 87(4), 301-303

8. Farhat M.H., Shamseddine A.I. and Barada K.A(2008). Small Bowel Tumors: Clinical Presentation, Prognosis, and Outcome in 33 Patients in a Tertiary Care Center. Journal of Oncology, 2008, 5.

\title{
ĐÁNH GIÁ HIÊUU QUẢ ĐIỀU TRI PHỤC HồI CHỨC NĂNG VÂN ĐộNG CỦA BỆNH NHÂN ĐộT QUỴ NHỒI MÁU NÃO BẰNG ĐIỆN CHẦM KẾT HỢP PHƯƠNG PHÁP TẬP BOBATH
}

\section{TÓM TÁ́T}

Mục tiêu: Đánh giá hiệu quả điều trị của điên châm kết hợp phương pháp tâp Bobath trong phục hồi chức năng vận động bệnh nhẩn liệt nửa người sau đôt quy nhồi máu não. Đối tượng và phương pháp: 60 bệnh nhân được chẩn đoán liệt vận động do đột quy. nhồi máu não sau giai đoạn cẩp, không phân biệt giới tính, tình nguyện tham gia nghiên cứu. Nhóm đối chứng được điều trì bằng điên châm, nhóm nghiên cứu điều trị như nhóm đối chứnq kết hơp tâp vận đônng theo phương pháp Bobath. Đánh giá thay đổi mức độ liệt theo thang điểm Henry, tình trạng lâm sàng và khả năng sinh hoạt độc lập sau 28 ngày điêu trị. Kết quả: Tỷ lệ BN chuyển được 2 độ liệt theo Henry ở nhóm nghiển cứu là 46,67\%; điểm Orgogozo trung bình của bệnh nhân nhóm nghiên cứu tăng từ $56,67 \pm 12,50$ trước điêu trị lên $85,67 \pm 9,54$ sau điêu trị, $50 \%$ bệnh nhân chuyển được 2 độ liệt; điểm Barthel trung bình của bệnh nhẩn nhóm nghiên cứu tăng từ 39,30 \pm 9,22 trước điều trị lên 72,70 $\pm 7,27$ sau điều trị, số bệnh nhân chuyển được 2 độ liệt chiếm $53,33 \%$, cao hơn có ý nghĩa so với nhóm đối chứng. Kết luận: Điện châm kết hợp phương pháp tâp Bobath có tác dụng điều trị phục hồi chức năng vận động trên các bệnh nhân liệt nửa người do đột quy nhồi máu não sau giai đoạn cấp.

Tư khóa: Đột quỵ não nhồi máu não, điện châm, tập Bobath.

\section{SUMMARY \\ EFFET OF ELECTRIC ACUPUNTURE}

\footnotetext{
${ }^{1}$ Bệnh viện Châm cứu Trung ương

${ }^{2}$ Viện Y hơc cổ truyền Quân đỗi

Chịu trách nhiệm chính: Nguyễn Đức Minh

Email: drminhchamcuu@gmail.com

Ngày nhận bài: 3/12/2021

Ngày phản biên khoa hoc: 2/1/2020

Ngày duyệt bài: 18/1/2021
}

\section{Nguyễn Đức Minh ${ }^{1}$, Nguyễn Vinh Quốc ${ }^{2}$ COMBINED WITH BOBATH PRACTICE IN MOTOR REHABILITATION THE REHABILITATION THERAPY IN PATIENTS WITH HEMIPLEGIA FOLLOWING AN ACUTE CEREBRAL INFARCTION STOKE}

Objective: To evaluate the effect of electric acupuncturecombined with Bobath practice in motor rehabilitation therapy in patients with hemiplegia following an acute cerebral infarction stroke. Subjects and Methods: 60 patients, being diagnosed with motor paralysis due to cerebral infarction stroke after the acute period, regardless of gender, volunteered to participate in the study. The control group was treated with electric acupuncture, the research group was treated the same but addedthe Bobath exercise method. Evaluation of change in degree of paralysis on Henry scale, clinical status and ability to function independently after 28 days of treatment. Results: The rate of patients who converted 2 degrees according to Henry in the research group was 46.67\%; The mean Orgogozo score in research group increased from $56.67 \pm 12.50$ before treatment to $85.67 \pm 9.54$ after treatment, $50 \%$ of the patients converted 2 degrees of paralysis; The average Barthel score in research group increased from $39.30 \pm 9.22$ before treatment to $72.70 \pm 7.27$ after treatment, the number of patients who converted 2 degrees of paralysis accounted for $53.33 \%$. Significantly higher than the control group. Conclusion: Electric acupuncture combined with Bobath practice method has the effect of restoring motor function in patients with hemiplegia after stroke after the acute period.

Keywords; Cerebral infarction stroke, electric acupuncture, Bobath

\section{I. ĐĂT VẤN ĐỀ}

Đột quy. não là một trong những nguyên nhân hàng đầu gây tử vong và tàn tật ở các 
quốc gia trên thế giới trong đó đột quy nhồi máu não (ĐQNMN) chiếm đa số với tỷ lệ $75 \%$ đến 80\% [1]. Liệt vận động sau ĐQNMN là nguyên nhân đứnghàng thứ 4 tạo ra gánh nặng cho người bệnh, gia đình và xã hội khi đánh giá bằng số năm sống với tàn tật (chỉ số DALY), chi phí điều trị và chăm sóc rất tốn kém [1]. Chính vì vậy điều trị phục hồi chức năng vận động sau ĐQNMN luôn là vấn đề cấp thiết trong y học nhằm hạn chế tử vong, phục hồi chức năng, giảm thiểu tối đa những tàn phế, nâng cao chất lượng cuộc sống của người bệnh, góp phần đưa người bệnh trở lại cộng đồng.

Bobath là một trong những phương pháp tập phục hồi chức năng cho bệnh nhân liệt vận động sau ĐQNMN được các thầy thuốc $Y$ học hiện đaiứng dụng phổ biến trên lâm sàng và đạt được kết quả tốt [2]. Điện châm là phương pháp chữa bệnh không dùng thuốc của $Y$ học cổ truyền đã được chứng minh có những đóng góp tích cực trong điều trị và phục hồi chức năng cho nhứng bệnh nhân ĐQNMN[3]. Kết hợp giữa những thành tựu mới của $Y$ học hiện đại và kế thừa tinh hoa của $Y$ học cổ truyền đang là $x u$ thế phát triển của y học với mong muốn nâng cao hiệu quả điều trị trong đó có bệnh lý ĐQNMN, nghiển cứu được thực hiện nhằm mục tiêu đánh giá hiệu quả điều trị của điện châm kết hợp phương pháp tập Bobath trong phuc hồi chức năng vận động trên bệnh nhân liệt nửa người sau ĐQNMN.

\section{II. ĐỐI TƯợNG VÀ PHƯƠNG PHÁP NGHIÊN CỨU \\ 2.1. Chất liêu}

- Máy điện châm M8 do Bệnh viện Châm Cứu trung ương sản xuất.

- Kim châm cứu 1 lần các cõ̃ phù hợp yêu cầu kỹ thuật, pince, bông, cồn $70^{\circ} \ldots$

- Phác đồ huyệt điều trị liệt nửa người củaBộ Y tế (Châm bổ các huyệt Tam âm giao, Huyết hải, Thái khê, Thận du, Âm cốc, Bạch hoàn du, Âm liêm. Liệt tay: châm tả các huyệt Giáp tích C4 - C7, Kiển ngung, Khúc trì, Bát tà, Hợp cốc, Ngoại quan, Kiên trinh, Đại chùy, Tích trung, Lao cung, Cực tuyền. Liệt chẩn: châm tả các huyệt Giáp tích D12- L5, Trật biên, Hoàn khiêu, Thừa phù, Ân môn, Thừa sơn, Ủy trung, Dương lăng tuyền, Lương khâu, Huyền chung, Bễ quan, Giải khê, Phi dương, Côn lôn) [4].

2.2. Đối tượng nghiên cứu. 60 bệnh nhân (BN) được chẩn đoán liệt vận động do ĐQNMN sau giai đoạn cấp, điều trị tại Bệnh viện Châm cứu Trung ương từ tháng 04 năm 2017 đến tháng 11 năm 2017. Tỉnh táo, đủ khả năng hợp tác với thầy thuốc, tình nguyện tham gia nghiển cứu, phù hợp với chứng trúng phong kinh lạc theo $\mathrm{Y}$ học cổ truyền[3]. Không đưa vào nghiển cứu các BN có bệnh phổi mãn tính, bệnh khớp, bệnh lý về máu, sau mổ, sau đẻ, phụ nữ có thai, lao, rối loạn tâm thần, HIV/AIDS.

2.3. Phương pháp nghiên cứu. Nghiên cứu can thiệp lầm sàng mở có đối chứng, so sánh kết quả trước và sau điều trị. Các $B N$ nghiên cứu được chia làm 2 nhóm:

- Nhóm đối chứng (NĐC): 30 BN được điêuu trị bằng điện châm theo phác đồ của Bộ Y tế. Mỗi ngày châm từ 15-20 huyệt, tần số từ $1-3 \mathrm{~Hz}$ là châm bổ, từ $5-10 \mathrm{~Hz}$ là châm tả, cường độ kích thích từ 1-60 $\mu \mathrm{A}$ tùy người bệnh. Châm ngày một lần vào buổi sáng, thời gian 30 phút/lần châm. Liêu trình 28 ngày.

- Nhóm nghiên cứu (NNC): 30 BN được điều trị như NĐC, kết hợp tập vận động theo phương pháp tập Bobath (bao gồm vận động thụ động, vận động chủ động có trợ giúp, vận động chủ động kết hợp các bài tập di chuyển)[2]. Mỗi ngày tập 1-2 lần, mỗi lần 30 phút, khuyến khích bệnh nhân chủ động, chỉ hỗ trợ khi cần thiết và giảm sự hỗ trợ càng sớm càng tốt, tập nâng dần từ dễ đến khó.

\subsection{Chỉ tiêu theo dõi và đánh giá}

- Đặc điểm chung các BN nghiên cứu (tuổi, giới, thời gian mắc bệnh)

- Thayđổi mức độ liệt theo thang điểm Henry, tình trạng lâm sàng (điểm Orgogozo) và khả năng sinhhoạt độc lập (điểm Barthel) trước và sau điều trị.

- Tác dụng không mong muốn trên lâm sàng của châm cứu: vựng châm, chảy máu, nhiễm trùng. Chỉ số mạch, huyết áp trước và sau điều trị.

2.5. Xử lý số liệu. Các số liệu được xử lý bằng phần mềm SPSS 16.0 for Windows. Các thuật toán được áp dụng: tính tỷ lệ phần trăm, tính số trung bình mấu, độ lệch chuẩn, so sánh số trung bình theo thuật toán T-Student.

\section{KẾT QUẢ NGHIÊN CỨU}

\section{1. Đặc điểm chung các đối tượng nghiên cứu}

Bảng 1. Phân bố đối tượng theo độ tuổi, giới và thời gian mắc bênh

\begin{tabular}{|c|c|c|c|c|c|c|}
\hline \multirow{2}{*}{\multicolumn{2}{|c|}{ Chỉ tiêu }} & \multicolumn{2}{|c|}{ Nhóm nghiên cứu } & \multicolumn{2}{|c|}{ Nhóm đối chứng } & \multirow[b]{2}{*}{$\mathbf{p}$} \\
\hline & & Số lương & Tý lế \% & Số lương & Tý lệ \% & \\
\hline \multirow{2}{*}{ Tuổi } & $\leq 49$ & 1 & 3,3 & 1 & 3,3 & $>0,05$ \\
\hline & $50-59$ & 7 & 23,3 & 6 & 20,0 & $>0,05$ \\
\hline
\end{tabular}




\begin{tabular}{|c|c|c|c|c|c|c|}
\hline \multirow{3}{*}{ Giới tính } & $60-69$ & 11 & 36,7 & 10 & 33,3 & $>0,05$ \\
\cline { 2 - 7 } & $\geq 70$ & 11 & 36,7 & 13 & 43,4 & $>0,05$ \\
\cline { 2 - 7 } & Nam & 16 & 53,3 & 17 & 56,7 & $>0,05$ \\
\cline { 2 - 7 } & Nữ & 14 & 46,7 & 13 & 43,3 & $>0,05$ \\
\hline \multirow{2}{*}{$\begin{array}{c}\text { Thời gian } \\
\text { mắcbệnh }\end{array}$} & $<1$ tháng & 21 & 70 & 20 & 66,7 & $>0,05$ \\
\cline { 2 - 7 } & $1-3$ tháng & 6 & 20 & 6 & 20 & $>0,05$ \\
\cline { 2 - 7 } & $>3$ tháng & 3 & 10 & 4 & 13,3 & $>0,05$ \\
\hline
\end{tabular}

Độ tuổi mắc bênh trên 60 chiếm tỷ lệ cao ở cả 2 nhóm (73,4\% ở NNC và 76,7\% ở NĐC). Tỷ lệ nam/nữ ở NNC (16/14) và NĐC (17/13) là tương đương $(p>0,05)$. Tỷ lệ BN mắc bệnh dưới một tháng của cả hai nhóm là lớn nhất, không khác biệt về thời gian mắc bệnh giữa hai nhóm BN nghiên cứu với $p>0,05$

\subsection{Kết quả điều tri}

Bảng 2. Sự thay đổi mức độ liệt (điểm Henry)

\begin{tabular}{|c|c|c|c|c|c|c|c|c|c|}
\hline \multirow{3}{*}{$\begin{array}{l}\text { Độ } \\
\text { liệt }\end{array}$} & \multicolumn{4}{|c|}{ Nhóm nghiên cứu } & \multicolumn{4}{|c|}{ Nhóm đôichứng } & \multirow[b]{3}{*}{ p2-4 } \\
\hline & \multicolumn{2}{|c|}{ Trước điêuu trị } & \multicolumn{2}{|c|}{ Sau điêu trị } & \multicolumn{2}{|c|}{ Trước điêu trị } & \multicolumn{2}{|c|}{ Sau điêu trị } & \\
\hline & $\begin{array}{c}\text { Số } \\
\text { lượng }\end{array}$ & $\begin{array}{c}\text { Tỷ lề } \\
\text { \% }\end{array}$ & $\begin{array}{c}\text { Số } \\
\text { lương }\end{array}$ & $\begin{array}{c}\text { Tỷ lệ } \\
\%\end{array}$ & $\begin{array}{c}\text { Số } \\
\text { Iươngng }\end{array}$ & $\begin{array}{l}\text { Tỷ lệ } \\
\text { \% }\end{array}$ & $\begin{array}{c}\text { Số } \\
\text { lương }\end{array}$ & $\begin{array}{l}\text { Tỳ lệ } \\
\% \%\end{array}$ & \\
\hline 0 & 0 & 0 & 4 & 13,33 & 0 & 0 & 3 & 10 & $>0,05$ \\
\hline 1 & 5 & 16,67 & 8 & 26,67 & 4 & 13,33 & 5 & 16,67 & $<0,05$ \\
\hline 2 & 7 & 23,33 & 9 &, 00 & 8 & 26,67 & 13 & 43,33 & $<0,05$ \\
\hline 3 & 14 & 46,67 & 6 & 20,00 & 15 & 50,00 & 7 & 23,33 & $>0,05$ \\
\hline 4 & 4 & 13,33 & 3 & 10,00 & 3 & 10,00 & 2 & 6,67 & $>0,05$ \\
\hline 5 & 0 & 0 & 0 & 0 & 0 & 0 & 0 & 0 & - \\
\hline Tống & 30 & 100 & 30 & 100 & 30 & 100 & 30 & 100 & \\
\hline
\end{tabular}

Sau điều trị, thay đổi độ liệt Henry đánh giá độ 1, độ 2 ở NNC cải thiện tốt hơn so với NĐC, khác biệt có ý nghĩa với $\mathrm{p}<0,05$.
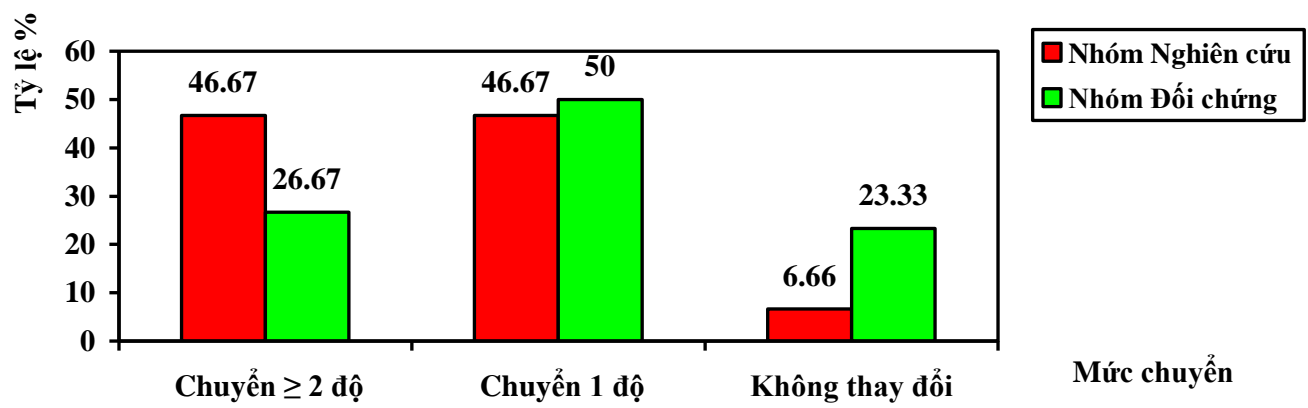

Biểu đồ 1. Mức chuyển độ liệt theo Henry sau điều trị

Tỷ lệ BN chuyển trên 2 độ liêt ở NNC là $46,67 \%$, cao hơn có ý nghĩa so với NĐC (26,67\%). 23,33\% BN ở NĐC không thay đổi độ liệt sau điêuu trị so với 6,66\% ở NNC, khác biệt có ý nghĩa thống kê $(p<0,05)$.
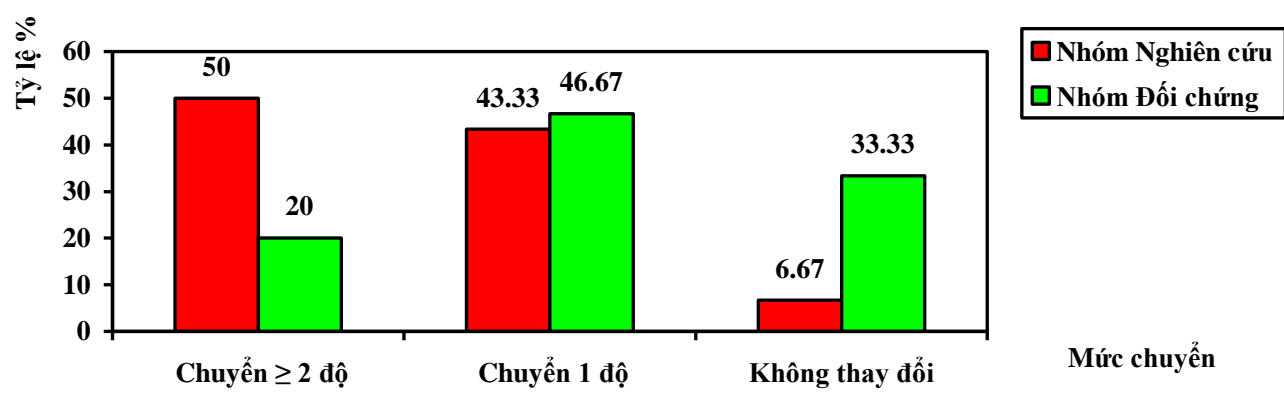

Biểu đồ 2. Mức chuyển độ liệt theo Orgogozo sau điều trị

BN ở NNC chuyển được trên 2 độ liệt chiếm tỷ lệ $50 \%$, cao hơn có ý nghĩ̃a so với NĐC (20\%). 
33,33\% BN ở NĐC không thay đổi độ liệt sau điều trị so với 6,67\% ở NNC, khác biệt có ý nghĩa thống kê $(p<0,05)$.

Bảng 3. Thay đổi điểm Orgorozo và điểm Barthel sau điều trị

\begin{tabular}{|c|c|c|c|c|}
\hline \multirow{2}{*}{ Điểm } & Nhóm nghiên cứu $(n=30 ; \overline{\mathbf{x}} \pm \mathrm{SD})$ & Nhóm đối chứng $(\mathrm{n}=30 ; \overline{\mathbf{x}} \pm \mathrm{SD})$ \\
\cline { 2 - 5 } & Trước điếu trị & Sau điều trị & Trước điều trị & Sau điều trị \\
\hline Orgorozo & $56,67 \pm 12,50$ & $85,67 \pm 9,54$ & $57,33 \pm 13,21$ & $72,10 \pm 9,38$ \\
\hline $\mathrm{p}$ & \multicolumn{5}{|c|}{$\mathrm{p}_{1-3}>0,05 ; \mathrm{p}_{1-2} ; \mathrm{p}_{3-4} ; \mathrm{p}_{2-4<0,05}$} \\
\hline Barthel & $39,30 \pm 9,22$ & $72,70 \pm 7,27$ & $37,40 \pm 9,05$ & $62,20 \pm 8,02$ \\
\hline $\mathrm{p}$ & \multicolumn{5}{|c|}{$\mathrm{p}_{1-3}>0,05 ; \mathrm{p}_{1-2} ; \mathrm{p}_{3-4} ; \mathrm{p}_{2-4<0,05}$} \\
\hline
\end{tabular}

Điểm Orgorozo trung bình và điểm Barthel trung bình sau điều trị ở cả 2 nhóm BN đều cải thiện tốt hơn có ý nghĩa so với trước điều trị. Mức cải thiện điểm Orgorozo trung bình và điểm Barthel trung bình sau điêu trị ở NNC tốt hơn NĐC $(p<0,05)$.
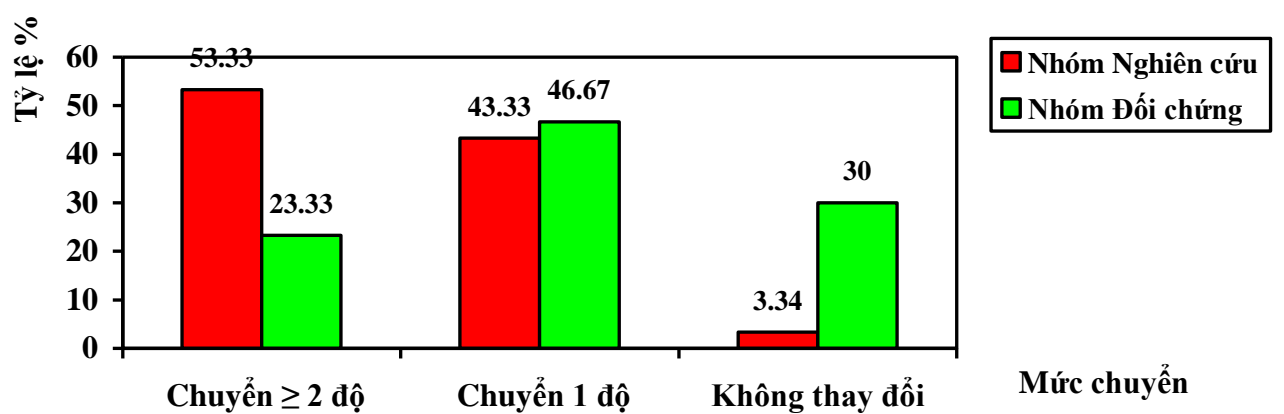

Biểu đồ 3. Mức chuyển độ liêt theo Barthel sau điều tri

Tỷ lệ BN chuyển được trên 2 độ liệt ở NNC là $53,33 \%$, cao hơn có ý nghĩa so với NĐC (23,33\%). $30 \%$ BN ở NĐC không thay đổi độ liệt sau điều trị so với 3,34\% ở NNC, khác biệt có ý nghĩa thống kê $(p<0,05)$.

3.3. Tác dụng không mong muốn. Trong quá trình điều trị, không thấy xuất hiện tác dụng phụ không mong muốn của châm cứu ở cả hai nhóm BN nghiên cứu: vựng châm, chảy máu, nhiễm trùng...

Bảng 4. Thay đổi tần số mạch, chi số huyết áp trước và sau điều trị

\begin{tabular}{|c|c|c|c|c|}
\hline Chỉ tiêu & Thời điểm & $\begin{array}{c}\text { NNC } \\
\left(n=30 ; \overline{\mathbf{x}}_{ \pm S D}\right)\end{array}$ & $\begin{array}{c}\mathbf{N D C} \\
\left(n=30 ; \overline{\mathbf{x}}_{ \pm S D}\right)\end{array}$ & PNC-DC \\
\hline \multirow{3}{*}{ Mạch (lần/phút) } & Trước điều trị & $82,6 \pm 7,7$ & $81,5 \pm 3,8$ & $>0,05$ \\
\hline & Sau điêu trị & $80,6 \pm 8,6$ & $80,3 \pm 3,9$ & $>0,05$ \\
\hline & Ptrước-sau & $>0,05$ & $>0,05$ & \\
\hline \multirow{3}{*}{$\begin{array}{l}\text { Huyết áp tâm thu } \\
(\mathrm{mmHg})\end{array}$} & Trước điều trị & $124,2 \pm 5,6$ & $118,1 \pm 5,8$ & $>0,05$ \\
\hline & Sau điêu trị & $121,8 \pm 5,6$ & $119,8 \pm 6,6$ & $>0,05$ \\
\hline & Ptrước-sau & $>0,05$ & $>0,05$ & \\
\hline \multirow{3}{*}{$\begin{array}{l}\text { Huyết áp tâm trương } \\
(\mathrm{mmHg})\end{array}$} & Trước điều trị & $74,3 \pm 5,9$ & $70,5 \pm 2,7$ & $>0,05$ \\
\hline & Sau điêu trị & $71,8 \pm 4,4$ & $71,1 \pm 3,3$ & $>0,05$ \\
\hline & Ptrước-sau & $>0,05$ & $>0,05$ & \\
\hline
\end{tabular}

Tần số mạch, chỉ số huyết áp ở cả NNC và NĐC sau điều trị không khác biệt so với trước điều trị $(p>0,05)$.

\section{BÀN LUẬN}

4.1. Đặc điểm chung các đôi tượng nghiên cứu. Kết quả nghiên cứu cho thây, độ tuổi mắc bệnh trên 60 chiếm tỷ lệ cao ở cả 2 nhóm (73,4\% ở NNC và $76,7 \%$ ở NĐC). Kết quả này phù hợp với nhận định của nhiều tác giả: ĐQNMN có xu hướng gia tăng từ độ tuổi trên 50 , tuổi thường găp là 60-70 tuổi do ở độ tuổi này có nhiều yếu tố nguy cơ kèm theo như tăng huyết áp, đái tháo đường, xơ vữa động mạch...[2], [5]. Tuổi cao cũng một trong nhũng nguyên nhân ảnh hưởng tới hiệu quả của quá trình điều trị phục hồi chức năng[2], [5]. Theo lý luận Y học cô truyền, tuổi càng cao nguyên khí càng kém, công năng tạng phủ, khí huyết hư suy, dinh vệ, tấu lý sơ hở... tà khí ở bên ngoài dễ xâm nhập gây nên bệnh[3].

Tỷ lệ nam/nữ ở NNC (16/14) và NĐC (17/13) là tương đương. Mối liên quan giữa giới và bệnh ĐQNMN chưa có bằng chứng rõ ràng và quan 
điểm thống nhất, Ngô Quỳnh Hoa (2013) nghiên cứu $90 \mathrm{BN}$ ĐQNMN nhận thấy tỷ lệ nam/nữ là 1,14/1[6]. Kết quả của chúng tôi tướng đồng với nhận định của nhiều nghiên cứu, tỷ lệ nam mắc bênh ĐQNMN nhiều hơn nữ và tỷ lề này có lẽ liên quan tới thói quen sinh hoạt và một số yếu tố nguy cơ khác thường gặp ở nam giới như hút thuốc lá, uống rượu bia, tăng huyết áp, rối loạn lipid máu...[1], [2], [5].

Tỷ lệ BN mắc bệnh dưới 3 tháng ở hai nhóm BN đều chiếm tỷ lệ cao ( $90 \%$ ở NNC và $86,7 \%$ ở NĐC). Tương tự nghiên cứu của Ngô Quỳnh Hoa, thời gian mắc bệnh dưới 3 tháng ở NNC là $88,89 \%$ và $\mathrm{NĐC}$ là $75,56 \%[6]$. Theo chúng tôi cần tận dụng tốt thời gian này để điều trị phục hồi chức năng vận động cho người bệnh, đầy cũng là nhận định củanhiều nghiên cứu lâm sàng: BNĐQNMN nếu được điều trị sớm thì khả năng phục hồi các tế bào não, phục hồi chức năng vận động sẽ tốt hơn so với điều trị muộn[1], [2], [5], [6], [7].

4.2. Kết quả điêuu trị. Theo YHCT, huyệt là nơi tiếp nhận các kích thích, tác động lên huyệt có thể phục hồi chức năng tạng phủ bị rối loạn, lập lại sự hoạt động bình thường của cơ thể. Trên cơ sở lý luận kinh lạc, việc chọn huyệt tại nơi bị bệnh và các kinh lạc đi qua vùng bị bệnh đã được xây dựng thành phác đồ [4],[7],[8]. Điên châm có tác dụng thông kinh hoạt lạc, điêu hòa khí huyết, tạng phủ và điều khí dấn huyết tới nơi bị liệt. Theo nghiên cứu $Y$ học hiện đại, điện châm giúp tạo phản ứng kích thích hệ thần kinh, qua đó tạo cung phản xạ kết nối quá trình liên lạc đến hệ thần kinh não bộ trong đó có trung khu vận động. Mặt khác, điện châm giúp cơ thể sản sinh các chất trung gian có tác dụng phục hồi chức năng bị tổn thương, những chất này có thể xem như thuốc tự thân [3], [8]. Nguyên lý Bobath cho rằng, phần lớn các mẫu vận động của con người là học được trong quá trình sống dựa trên các phản xa có điều kiên, các mấu vận động này bị mất đi hoặc bị ức chế do các tổn thương thần kinh ở não. Do đó kỹ thuật của Bobath nhằm khôi phục và học lại các mẫu vận động bình thường vốn đã có trước khi tổn thương thần kinh, loại bỏ các mẫu vận động bất thường bằng cách sử dụng các kỹ thuật ức chế phản xạ, giúp BN học lại cảm giác vận động hơn là lấy động tác và làm mạnh cơ là chính. Các động tác vận động phía bên liệt được chú ý để tạo kích thích, và kích thích được dẫn truyền theo các đường dẫn truyền hướng tâm lên bán cầu não bị tổn thương để khôi phục lai các mẫu vận động vốn có[2]. Đây cũng là cơ sở khoa học để chúng tôi thực hiện nghiên cứu này.

Sau điều trị, thay đổi độ liệt Henry đánh giá độ 1, độ 2 ở NNC cải thiện tốt hơn so với NĐC, khác biệt có ý nghĩa thông kê. Tỷ lệ BN chuyển được 2 độ liệt ở NNC là 46,67\%, cao hơn có ý nghĩa so với NĐC. 23,33\% BN ở NĐC không thay đổi độ liệt sau điều trị so với 6,66\% ở NNC, khác biệt có ý nghĩa thống kê. Kết quả của chúng tôi cũng tương tự như nhận xét của Nguyễn Thị Ngọc Lan khi nghiên cứu khả năng phục hồi vận động của $B N$ ĐQNMN cấp bằng kỹ thuật Bobath: ở nhóm can thiệp bằng kỹ thuật Bobath phần lớn BN tiến triển tốt hơn, co cứng cơ giảm, BN thực hiện được vận động các khớp cũng tốt hơn [2].

Thang điểm Órgogozo với mười tiêu chí đánh giá trạng thái chức năng thần kinh của $B N$ đột quy nã̃o trên cơ sở lượng giá điểm của từng triệu chứng [1],[5]. Điểm Orgogozo trung bình của BN NNC đã tăng từ $56,67 \pm 12,50$ trước điều trị lên $85,67 \pm 9,54$ sau điều trị, ở NĐC lần lượt là $57,33 \pm 13,21$ và $72,10 \pm 9,38$, mức cải thiện điểm Orgorozo trung bình sau điều trị ở NNC tốt hơn có ý nghĩa so với NĐC. Số BN ở NNC chuyển được 2 độ liệt chiếm tỷ lệ $50 \%$, cao hơn có ý nghĩa so với NĐC. Điểm Orgogozo trung bình trong nghiên cứu của chúng tôi cao hơn so với Phạm Thị Ánh Tuyết (2013) khi đánh giá hiệu quả điều trị của phương pháp cận tam châm trển BN liệt nửa người do ĐQNMN sau giai đoạn cấp nhận thây điểm trung bình Orgogozo của nhóm nghiên cứu là $37,71 \pm 11,39$ và nhóm chứng $38,43 \pm 12,93$ [7], nhưng thấp hơn kết quả của Vương Thị Kim Chi (2009) dùng phương pháp xoa bóp, vận động kết hợp điện châm trong phục hồi chức năng vận động cho $\mathrm{BN}$ ĐQNMN, điểm trung bình Orgogozo sau điều trị là 95,68 $\pm 4,31$. Theo chúng tôi, kết quả này có thể do sự khác biệt về thời điểm thực hiện nghiên cứu cửng như lựa chọn đối tượng nghiên cứu. Để có thể nhận định khách quan và đầy đủ hơn, cần tiếp tục có các nghiên cứu đánh giá tiếp theo.

Thang điểm Barthel nhằm đánh giá mức độ độc lập về mặt chức năng trong sinh hoạt hằng ngày của BN đột quy não [1], [5]. Kết quả bảng cho thấy điểm Barthel trung bình của BN NNC đã tăng từ 39,30 $\pm 9,22$ trước điêu trị lên $72,70 \pm$ 7,27 sau điều trị, ở NĐC lần lượt là $37,40 \pm 9,05$ và $62,20 \pm 8,02$, mức cải thiện điểm Barthel trung bình sau điều trị ở NNC tốt hơn có ý nghĩa so với NĐC. Số BN ở NNC chuyển được 2 độ liệt chiếm tỷ lệ $53,33 \%$, cao hơn có ý nghĩa so với NĐC. Kết quả nghiên cứu của chúng tôi cho thây kết hợp giữa điện châm và phương pháp tập Bobath rất có hiệu quả trong cải thiện mức độ 
liêt, tình trạng lâm sàng và khả năng sinh hoạt độc lập của BN ĐQNMN.

Trong quá trình nghiên cứu, không gặp tai biến chảy máu, nhiễm khuẩn tại chỗ..., điều này cho thây trình độ và năng lực của kỹ thuật viên Bệnh viện Châm cứu Trung ương khi thực hiện kỹ thuật châm cứu. Không nhận thấy ảnh hưởng của phương pháp tới các chỉ số mạch, huyết áp trên các đối tượng nghiên cứu. Kết quả này góp phần minh chứng thêm cho tính an toàn của phương pháp kết hợp điện châm và tập Bobath, vì vậy có thể triển khai rộng rãi phương pháp này.

\section{KẾT LUẬN}

- Điện châm kết hợp phương pháp tập BoBathcó tác dụng điêu trị phục hồi chức năng vận động trên các bệnh nhân liệt nửa người sau đột quỵ. nhồi máu não. Sau 28 ngày điêuu trị, 46,67\% bệnh nhânở nhóm nghiên cứuchuyển được 2 độ liệt theo thang điểm Henrry, cao hơn có ý nghĩa so với nhóm đối chứng. Điểm Orgogozo trung bình sau điều trị của nhóm nghiên cứu là $85,67 \pm 9,54,50 \%$ bệnh nhân chuyển được 2 độ liệt, cao hơn có ý nghĩa so với nhóm đối chứng. Điểm Barthel trung bình của nhóm nghiên cứu sau điều trị là $72,70 \pm 7,27$, $53,33 \%$ bệnh nhân chuyển được 2 độ liệt, cao hơn có ý nghĩa so với nhóm đối chứng.

- Điện châm kết hợp tập Bobath không gây tác dụng không mong muốn trên lâm sàng, không ảnh hưởng bất lợi tới chỉ số mạch, huyết áp sau 28 ngày điều trị ở tất cả các bệnh nhân nghiên cứu.

\section{TÀI LIÊU THAM KHẢO}

1. Nguyễn Văn Thông (2008). Đột quy não - cấp cứu - điều trị - dự phòng, NXB Y học, Hà Nội.

2. Nguyễn Thị Ngọc Lan, Nguyễn Thị Kim Thủy (2011). Đánh giả kết quả phưc hồi chức năng vân động của bệnh nhân nhồi máu não cấp băng kỹ thuật Bobath. Tạp chí Y học thực hành, 798 (12), 100-103.

3. Bố môn $\mathbf{Y}$ học cổ truyên - Trường Đai học $\mathbf{Y}$ Hà Nôi (2005). Bài giảng Y học cổ truyển tập II, NXB Y hoc, Hà nôi, 151-153.

4. Bộ Y tế (2013). Quyết định số 792/QĐ-BYT về việc ban hành Hướng dẫn Quy trình kỹ thuât khám bệnh, chữa bệnh chuyên ngành Châm cứu. Quy trình số 102: Điện mãng châm điều trị liệt nửa người do tai biến mach máu não, Hà Nôii.

5. Mai Duy Tôn (2014). The Lancet - Tiểp cận xử trí trong thần kinh học. Đột quy não, Nhà xuất bản Thế giới, 133-180.

6. Ngô Quỳnh Hoa (2013). Nghiên cứu tính an toàn và tác dung của thuốc "Thông mạch sơ lạc hoàn" trong điểu trị nhồi máu não sau giai đọạn cấp, Luân án Tiến sĩ Y học, Trường Đại học Y Hà Nội.

7. Phạm Thị Ánh Tuyết (2013). Đ̇ánh giá hiệu quả điều tri của phương pháp cân tam châm trên bênh nhân liệt nưa người do nhồi máu não sau giai đoạn cấp, Luận văn tốt nghiệp bác sỹ nội trú, Trường Đại hơc Y Hà Nội.

8. Nguyển Tài Thu, Trân Thúy (1997). Châm cứu sau Đại học, NXB Y học, Hà Nội.

\section{ĐĂC ĐIỂM LÂM SÀNG, CÂN LÂM SÀNG VÀ TÍNH KHÁNG THUỐC Ơं BÊNNH NHÂN LAO PHỔI TÁI PHÁT ĐIỀU TRI TAI BÊNH VIÊ̂N PHẠM NGỌC THẠCH, THÀNH PHỐ HỒ CHÍ MINH}

\section{TÓM TẮT}

Mục tiêu: Mô tả đăc điểm lâm sàng, cận lâm sàng ở bệnh nhân lao phổi tái phát. Đối tượng và phương pháp: $56 \mathrm{BN}$, nam/nữ= $2.3(39 / 17)$. Nam găp nhiều ở lứa tuổi từ $18-70$, nữ gặp nhiêu từ 18 tuổi đến 40 . Nghiên cứu tiến cứu, mô tả cắt ngang, theo dõi doc trên 56 bênh nhân lao phổi tái phát được đăng ký điều trị nội, ngoại trú tại Bệnh viện Phạm Ngoc Thach, thành phố Hồ Chí Minh, trong khoảng thời gian 02 tháng. Kết quả: Triệu chứng toàn thân

*Đại họ Y khoa Phạm Ngọc Thạch Chịu trách nhiệm chính: Đặng Vĩnh Hiệp Email: hiepdv@pnt.edu.vn Ngày nhận bài: 14/11/2020 Ngày phản biện khoa học: 22/12/2020 Ngày duyệt bài: 29/1/2021

\section{Đặng Vĩnh Hiệp*}

gặp nhiều nhất là sốt 57,14\%; Triệu chứng cơ năng phổ biến nhất là ho kéo dài $71,43 \%$. Triệu chứng thực thể nghèo nàn, ran nổ gặp tỷ lệ 39,28\%. X quang phổi: tổn thương phổi phải nhiều hơn phổi trái (46,43\% so với $32,14 \%)$, thâm nhiễm không thuần nhất chiếm tỷ lệ cao nhất, $64,28 \%$. Kết quả xét nghiệm AFB đờm (+) chiếm 58,93\%, AFB âm tính $41,07 \%$. Có 12 bênh nhân kháng INH chiếm 21,42\%; có 5 bệnh nhân kháng RMP + INH chiếm $8,93 \%$ và 39 bệnh nhân không kháng, chiếm 69,64\%. Kết luận: Lao phổi kháng thuốc hay tái phát là vấn đề luôn có tính thời sự. Việc điều trị khó khăn và phức tạp hơn bệnh lao mắc mới. Nghiên cứu về lâm sàng và xét nghiệm là cần thiết và có tính khoa học, ứng dụng thực tiên cao. phát.

Tư khóa: Lao phổi, lao kháng thuốc, lao phổi tái 